\title{
(a) The Experience of Motor Disability
}

Hans Bleeker

and

Karel J. Mulderij

University of Utrecht

How are you supposed to feel if the children from your neighborhood don't believe that you are 10 years old because, due to a growth deficiency, you only look about seven years old? Or, if your handicap is hardly visible, for example if you have brittle bones, how do you explain to others what is the matter with you? And how do you feel about that? Questions of this nature emerged from children's stories, and these questions determined the direction of our work. ${ }^{1}$ Living with physically handicapped children reveals how the presence of a handicap colors one's existence. A properly functioning body may be taken for granted by healthy children, but for the motor handicapped child it has to be literally won with sweat and tears by means of various types of therapy. Exercise, exercise, and still more exercise!

A few years ago, when comparing childhood with adulthood, Beekman (Bleeker \& Mulderij, 1984) stated: "The child is capable, not always, though certainly a great deal more often than adults, of seeing the world as an open field. The life of a good childhood is like a morning full of promise: its ripe fruits can be plucked later" (p. 74). We agree with Beekman's sentiment, however, as far as physically handicapped children are concerned, his evocative statement must be relativized. Depending on the type and severity of a child's handicap, the world can already be experienced as inaccessible, even at a young age. Instead of an open field, it is a field full of obstacles where every step forward is made with great difficulty. And as for the morning being full of promise, these children will regularly hear from their parents and from professionals that it is necessary to seize as much of this promise now, because later is often too late. Learning how to walk, cycle, talk, gain control of saliva, use the washroom, and countless other skills can only be acquired slowly and with a great deal of effort.

We started our project at a special Mytyl school for motor disabled children. We participate in the daily activities of a class of 10 children ranging in age from six to 10 years old. We are present at classes in

Phenomenology + Pedagogy Volume 101992 
physiotherapy, speech therapy, physical education, swimming, and playtime. Then we have our lunch together with the children. We each keep a logbook. We have short interviews with children about various aspects in their daily lives.

In addition, we visit 15 children once or twice a year at their homes throughout the Netherlands. Some of these children are from the Mytyl school. In this way we follow their progress over a number of years. The home visits yield observational reports and interview data. We also hold group interviews with adolescents between the ages of 14 and 20 . We are especially interested in their childhood memories, but we also ask them about their present experiences. All interviews are taperecorded and transcribed verbatim.

An additional (rather unorthodox) manner of data collecting is our work as volunteers for a week at an annual camp for physically handicapped children. All week we are on the move with the children round the clock, involving them in activities and taking care of their personal needs. Late in the evenings we discuss the events of the day and keep an oral $\log$ with the tape-recorder.

\section{Corporeality According to Merleau-Ponty}

The concept of corporeality occupies a central place in our study. Obviously our children live an existence where their physical functioning is to some degree restricted. All human beings are in complex ways dependent on their bodies, and if our body gets damaged then various problems soon follow. Even when it is functioning normally, our body is of fundamental importance to our existence, though we may not always be quite aware of this. The French philosopher Merleau-Ponty (1962) points out that not only do we have a body with which we can do everything, but that we also are our body. In taking this stance, he criticizes the "objective thinking" of empiricists and rationalists who create an unbridgeable gulf between the cognizant subject on the one hand and the world of objects on the other. When we go about our daily business we are usually little aware of our body as we live it. We might say that our body is the silent, taken-for-granted base from which we act on and learn about the world. It is silent because we are not usually conscious of it. Sartre shows how the taken-for-granted body is a body passé sous silence, passed over in silence (1943, pp. 368-427). Objective thought is only possible thanks to this. Merleau-Ponty (1962) uses the term corps-sujet, to indicate that this preobjective existence in the world is nothing other than physical being.

Only in special circumstances or situations do we become aware of our body. The person who simply walks up the stairs is oriented to the place where he or she wants to go. In this situation we are not oriented to our body; rather, we have passed over, glossed over our body. If we 
sprain our ankle, however, and subsequently want to climb the stairs, then it is no longer a matter of course. The staircase has now become a barrier. In such a situation we say: "I" cannot get up the stairs, despite the fact that it is only the ankle that hurts. This is what is meant when we say that we are our body (as well as have a body). In this situation the body has become the central theme in our existence. The body affects the way we are in the world and may become the conscious object of our attention.

What does all this mean for the child with a motor disability? Van den Berg (1950) suggests that the invalidity of the body is also generally passed over. The invalid person lives his or her body, and in order to be able to live the invalid will have to be able to forget his or her body just like the healthy person. Yet the way in which the invalid is confronted with this task proves his or her invalidity. This task becomes laborious. The motor disabled person meets insurmountable obstacles or experiences shaming failure (p. 408). For children with a motor disability, the body is also generally passed over in silence; more frequently, however, than for healthy children and in a different way the body becomes a theme in existence.

In the world of motor disabled children both the taken-for-granted, passed over body and the body as object become a central theme of their experience. In the taken-for-granted body one forgets that one relies on it; the body is not experienced as such. However, physical experiences stand out against the background of the taken-for-granted body. A clear example of this is physical vitality. Childhood existence is generally characterized by a great abundance of movement, and although the motor disabled child's body fairly regularly refuses to do what the child wants it to do, the need for vitality is not frustrated in every respect. The body that is passed over in vitality is an important part of motor disabled children's existence as well.

\section{The Vital Body}

We may distinguish three types of experience of physical vitality unconditional, conditional, and substitutive vitality.

Unconditional experience of vitality. During our research at the Mytyl school in Utrecht we are frequently in the playground during lunch breaks and at recess times and things are always very lively there. Children race down a hill in their wheelchairs or on their threewheelers. They get into a large swing in their wheelchair and we always see the children enjoying the speed they can work up in this way. A lively game such as tag is also a favorite. With cheeks red from exertion, the children chase each other in their wheelchairs; the need for movement is very clear. 
Arjen shows us his muscles: "I've got really strong arms," he tells us proudly. This is just as well because Arjen competes in wheelchair racing and he has a special wheelchair for this, a Speedy Wheely. $\mathrm{He}$ trains for these races in the neighborhood of his home and is pleased as punch with his speed and stamina. Arjen points at his medal with pride: "Yes, I won that, in a one and a half kilometer race." And what is the big attraction of wheelchair racing? "Well, it means you're moving about," says Arjen, "otherwise you get so lazy. I just do it for fun."

The activities of Arjen and his friends on the playground exemplify the experience of unconditional vitality. For them the body is not experienced as restrictive of free movements; this body is not in the way of their play and sport activities.

Conditional experience of vitality. In contrast, the conditional experience of vitality allows only under certain conditions, and only with assistance, for the sensation of free movement. Swimming is a good example of this. Practically all the children we talk to enjoy swimming. In the water their potential for movement is much greater than in their wheelchairs. Wouter is a seven-year-old boy with cerebral palsy. We cannot let him speak for himself here because his only method of communication is by means of sign language. But when we go swimming, it is immediately obvious that he is extremely mobile in the water. Wouter swims as well as he is able, and he manages to move all around the pool, enjoying himself thoroughly. Vanessa shouts at us: "Look, I can stand up straight and I can walk!" In the water she can only walk a little and do some other things such as sort of stand up straight with the help of a teacher.

The substitutive experience of vitality. Nine-year-old Roelof is too severely disabled to take part in sport himself, but he greatly enjoys watching his brother. Ineke accompanies her friend, who is not motor disabled, to jazz dance classes. "I enjoy that, it is so nice to watch," she says. Roelof's and Ineke's experience of body vitality is substitutive. If one cannot take part in sports oneself then it is still possible to experience the vitality vicariously by watching the children on the playground, by attending one's brother's gymnastic competitions, or one's friend's dance classes. In this way body experience can still be part of handicapped children's lives. Substitutive experience of vitality allows the child, by watching, to feel sympathetically in his or her own body what is happening in the body experience of other children.

\section{The Rebellious Body}

When the body protests, is uncooperative, and does not want to do what you want it to do, then the body appears as a theme that we may call the rebellious body. This "wanting to but not being able to" is often connected with the need for vitality as described above. In play situa- 
tions this is obvious. A child spontaneously wants to participate and play soccer, skip rope, climb trees, and all the other things that children do, but the handicapped child can only do these things a little or not at all.

"When they run off really fast, I feel jealous," says Laura. "I can't do what they're doing."

"When we're playing soccer I often think to myself, if only I could keep up a bit longer, if only I could play in actual matches or something like that," says Ivar.

In situations like this, children all too often experience their bodies as spoilsports and that can lead to all kinds of reactions. A child may feel jealous, angry, annoyed. A child may refuse to acknowledge the handicap by stubbornly trying again and again. And finally, all too often follow feelings of resignation, defeat, or acceptance.

Sometimes we ask children about this: "Ivar, do you feel angry when you see other children doing things that you are not able to do?"

"No, that doesn't make me angry."

"No? don't you even think a little bit that it's unfair?"

"No, no, I don't ... I just can't, just can't."

Ten-year-old Ivar seems to have attained a certain degree of acceptance.

Even outside this relationship with vitality, however, our children are confronted with limitations in their freedom of movement. For example, someone in a wheelchair who drops something on the ground is not usually capable of picking it up himself or herself, so help is required.

If you are a motor disabled child, then sometimes your body does allow you to do what you want to do, but only very slowly. You can go to the toilet yourself, you can dress yourself, you can eat on your own, but it takes an eternity and demands huge amounts of effort. Sometimes the exertion is so severe that you have to rest for a long time, and then the question arises whether this victory over your rebellious body was worthwhile, because now you can hardly muster the energy to do other things.

You may also have to concentrate very hard on all kinds of things because otherwise you won't manage them. Twelve-year-old cerebral palsy sufferer Pieter, who so wants to learn to walk, says: "I keep falling and, uh, if I don't concentrate I can't walk.... But walking by myself, I'll take a few steps, I'll be able to walk by myself, but really really walking around by myself, I can't see myself doing that, ever. 
Look, and I think that later some time, I'll be able to walk with one stick or something. That might happen some time."

The body can also be a spoilsport in communication with others. If you are physically disabled, you may want to say all sorts of things but you're trapped in your body because the words won't come out of your mouth. When that happens you communicate with your eyes or by means of a letter board or Bliss, a symbolic language. However, pointing to letters or symbols requires exertion too, and sometimes your arm flies in every direction except the one you want it to go. In the rebellious body, the child experiences a body that can contradict his or her intentions, a body that manifests itself as an obstacle and accordingly is very prominent in experience. In his book Under the Eye of the Clock, Nolan (1987) gives a compelling account of the way a handicapped child successfully demonstrates fine control of his rebellious body:

Making fun for the class became the custom and this particular day handsome Eamonn Campbell donned the comic's robe. He let the air out of the tires of the two wheels of Joseph's wheelchair. Then he defied Joseph to tell the teacher. Miss Ryan entered the classroom after the coffee-break and, determined not to fail, Joseph set about making his complaint. He peddled furiously on the footrest of his chair in order to catch her attention. She glanced down at Joseph. He peddled more furiously building up to a great crescendo while at the same time keeping a wary eye on her face. She frowned and then an enquiring look lit up her face. Joseph then caught her gaze and with his eyes drew her sight downwards to his flatrimmed wheel. He repeated his sweeping eye course until she walked down to stand before him and to look closely into his eyes. He drew her eyes downwards to his wheels. "What's wrong Joseph, is something wrong with your chair?" she asked. He nodded his offended nod and she glanced hard at his wheel. "Oh you've got a puncture," she said. Joseph looked into her face and swung her gaze to the other wheel. Keeping his head turned towards the other wheel she walked around to the other side of his chair. "Oh, someone let the air out of your wheels," she observed. "Who did that?" she demanded, but Joseph jumped into action and nodded accusingly at Eamonn. (pp. 17-18)

\section{The Unreliable Body}

It is a sunny afternoon and we are visiting Jane and take her out into the neighborhood. Karel pushes her wheelchair, the three of us are cracking jokes. Karel races into a hedge with Jane and she bursts out laughing in her wheelchair. A second time, a third time, and suddenly she is quiet and a minute later, she is in tears. What has happened? She has been laughing so much that she has wet her pants and now she is afraid of angry words or worse when she gets home. This is a regular occurrence with children with cerebral palsy. With children with spina bifida one has to be alert: if you are not sure to place a new catheter on time, then you have wet pants. Children with spina bifida cannot rely 
on their bodies in other respects too. For instance, many children have a pump in their heads to siphon off superfluous brain fluid. Brigitte is tussling with some other children and falls out of her chair. She falls on the grass. The fall is not hard, but her very first reaction is to put her hands to her head crying, "my drain, my drain." She knows that she is vulnerable there, and there's a touch of panic. Luckily, the situation is not serious and nothing is the matter with her.

Falling down is a clear example of the unreliability of the body. It takes you by surprise. Tessa fell out of her wheelchair and broke her arm: "Well, we were speeding down the block when suddenly my wheels jammed. But my mum told me to move my fingers, for if I could then my arm wouldn't be broken. But it was, right here." In this case one could object that the unreliability is in her wheelchair, not in her body. However, motor handicapped children experience the body and wheelchair relation in a different way; for them the wheelchair is an extension of the body.

Children who have little or no sensation in their limbs have to face other problems. Johan has broken his legs a few times already because of lack of sensation: "I got caught behind the leg of the table once and my parents were in the car and, uh, I get off my chair and start to crawl. My left leg is behind me and I go on, I crawl on, and my leg, and, and I hear a crack, I say, 'Mum, I heard my leg crack.' My leg's getting all fat and fatter. I went and lay down on my bed and phoned for an ambulance. My leg in splints. Six weeks on my back. I had to forget about the whole holiday."

"Didn't you feel anything?" we ask. "No, no, nothing, that's the bad thing."

Children with brittle bones have similar experiences, their bodies are not rebellious, but extremely unreliable. Stumbling over a flight of steps may cause a fracture. It goes without saying that for these children it is difficult to value taking the risk of repeating certain actions.

Children may also profit from the numbness mentioned above. When romping on the schoolyard Nicky is able to force me to the curb with her wheelchair. In order to stop her wild action, I try to grab her legs firmly. Teasingly she says, "Ha, ha, I won't feel that anyway!"

The unreliable body often has associated feelings of uncertainty. Liesbeth is learning to walk with crutches but she finds somewhat frightening. She is scared that she will fall over. Her problem is that she cannot get up once she is on the ground. The prospect of lying on the ground alone and being unable to get up makes her unsure of herself. Janneke always gets a fright when she suddenly notices someone standing 
behind her. She does not hear the children coming, and this makes her feel unsafe in many places.

Besides wetting their pants, falling down, and breaking arms or legs, various other minor accidents may be the experience of children with cerebral palsy because they cannot trust their own movements. There is the feeling of powerlessness that can happen to you as a result of your uncontrollable muscles. Nolan (1987) provides a vivid description of this powerlessness:

Joseph sat among his classmates but his handicap was scurrilously fretfilled. He was castrated by crippling disease, molested by scathing mockery, silenced by paralysed vocal muscles yet ironically blessed with a sense of physical well-being. He felt cheated though, for his healthy feeling seemed to vex his limbs into rebellion. The frenzied limbs could wreak involuntary havoc yet he was unable to even brush a fly off his nose ( $p$. 16).

Many motor disabled children experience that their bodies have let them down at unexpected moments. This can lead to a certain degree of suspicion with regard to the reliability of one's own body. The body is regarded with uncertainty, and in extreme cases the child experiences a fundamental feeling of insecurity.

\section{The Sensitive Body}

The body has its own specific sensibilities and susceptibilities. When pain occurs the body demands undivided attention. Illness, tiredness, or severe muscular tension can also cause the normal orientation to the world to be disrupted and deflected toward the body.

Hakan complains that he keeps waking up at night. The specially preformed bed in which he can hardly move gives him sore legs. Hakan finds it very difficult to adjust his body for comfort: "Then my legs hurt and I lie like this, but I'm supposed to lie like that." Even while sleeping, the handicapped child may be constantly reminded of the sensitive body.

For many of the young children the application of a catheter is an especially unpleasant experience. The catheter has to be used several times a day and it often hurts. Even the spina bifida child who feels no sensation has to be very careful. Monique is nine years old and she is already quite experienced in applying the catheter herself; but she still worries about not applying it properly. "It worries me that I might go wrong somewhere." The very fact that one feels no sensation is strangely special bodily sensibility.

Children like Ina who sit all day in an electric wheelchair occasionally hear from other children: "You sit in a wheelchair so you won't get tired." But Ina confides that it is no fun being in a wheelchair all day 
long. "It does make me tired, you know, sitting like this all day." Even the most comfortable position is uncomfortable if one cannot move at all.

Muscular tension is a sensibility that is specific to children with cerebral palsy, and with which they are all familiar to a greater or lesser extent. Henk's muscles turn stiff very quickly. His posture is cramped practically all day long. When we put Henk in the bath at night he says that this is the first moment of the entire day that he feels nice and relaxed. This is also a good moment to go to the washroom since bowel movements are that much easier now. Marjolein, who attends an integrated grade six class, complains that she can never go swimming with the rest of the class. "Of course, I can swim a bit too; well, not really. But, still, I can swim a bit. But then the open water is just too cold for me anyway. I can't go in if it's colder than 28 degrees, then, brrr! Outdoor swimming pools hardly ever get that warm. So, when all the others go swimming, well, I mean, then I can't join in ... it's just too cold."

Besides being especially sensitive, the handicapped body is frequently also susceptible to infection. So Ellen only goes outside when she is well wrapped up so that she does not catch a cold. She is used to this and quite understands it, but it is still difficult when the sun is shining and all the other children are walking around outdoors in their T-shirts. Gerard can tell exactly when the umpteenth bladder infection is on the way and what it feels like if your drain is not working properly. "Usually a pain in my head, a bit grumpy, a bit dozy; yes, because if I feel a tension in my head, then I have to get straight to the hospital."

Going to the hospital for check-ups, operations, or adjustments is a regular occurrence. Many children have detailed stories about it. ${ }^{2}$ Gerard points at his hip: "Cause I was operated here and then there. There were about 10 stitches in it. And I had one of these really long plasters that was this wide ... and they pulled it off like this. In one zip, just like that! It really hurt! And then they started taking these little knots out and there was one that wouldn't come undone. Right here ... one would not come out ... It really hurt!"

\section{The Exercise Body}

The body demands a certain maintenance. All kinds of therapy and "repair jobs" are performed on the children. How do the children feel about this? For many it is such a common procedure that they hardly think twice about it. That is not to say that the therapy is enjoyable! But, if you are a motor disabled child, therapy is as much part of life as going to bed every day. And just as you don't always feel like going to bed, so you don't feel like going for therapy. 
We regularly accompanied Francisca to therapy at the Mytyl school in Utrecht. Francisca had to exercise with her leg braces. The first few times she screamed in agony. Understandably she did not particularly like therapy. But when the braces said click for the first time, and when they finally felt secure on her legs, she felt so proud that she had managed it. From then on she insisted that she would wear the braces. When the holidays started approaching she realized that she would have to miss a week of exercise, and she was afraid that the progress of the past week would be lost. In other words, she experienced her physical improvement as a strong motivation, and the physiotherapy became a positive factor in her life that provided successes in which she could feel pride.

Francisca only exercises at school and not at home, but for many children the situation is different. They take their therapy home with them. This means that therapy is not limited to two or three hours with the therapist, but that it dominates a much greater area of existence. Children who are expressly told by their therapists (and their parents) to make sure and pay attention to their posture all day experience the body as an even stronger presence. Johan has therapy at school, in the hospital, and at home; and when we are sitting on the floor while talking with him, he says, "I'm not allowed to sit like that, because it would give me crooked legs." Life without therapy is unimaginable for Johan. Fortunately, it has beneficial effect. Recently he had another extremely complicated leg fracture, but now he is again able to crawl through the room.

Therapy is by far more enjoyable, or at least less unpleasant, if it produces results. Nine-year-old Liesbeth tells us that she has learned how to ride a bike during therapy. "We're not finished yet, I'm still learning, but I can ride the bike, I just can't sit on the saddle yet." And when Laura is asked if she can tell whether she has improved, she says emphatically "Loads! I couldn't even walk before. I just lay on my tummy and I moved about like that, just crawled with my hands ... Finally I knew I could walk, I thought to myself 'I can do it! I can do it! I can do it! And then I could do it ... Well, not straight away, the therapist had to teach me like, uh, foot for foot. Foot for foot she taught me. I was so happy about it."

Children experience pride in personal achievements. The experience that one's own body can do something it was not capable of before is of great significance for the children. Of course, not all exercise is fun. Exercises for learning to fall, for instance, are unpleasant. "I'm always so scared I fall beside the mat or something," says Monique. She does understand why she has to learn this, though. "It means I'm not so scared if I fall, I can catch myself." However, Monique's classmate Hakan had falling exercises also, and when he fell a while ago, he 
forgot what he had been taught in physiotherapy and tore a ligament. He had to wear his arm in a sling and use a wheelchair for weeks because he could not walk with one crutch. Other children see this kind of accident and it increases their doubts about whether they would be capable of actually applying the things they have been taught.

Peter is eight years old. He does not enjoy physiotherapy because it often hurts him, and when he is not attending school during the summer holidays he does not notice any difference. If Peter had his way his days of therapy would be over: "I could play more often." Therapy that does not produce any noticeable progress but that does exact a great deal of time and pain is not very motivating.

The one form of therapy that is to Peter's taste, and likewise to the taste of almost all children, is swimming. The warm pool makes the muscles feel relaxed, and the handicapped child enjoys more freedom of movement in the water. Swimming offers the child opportunities for the experience of vital body movement. Once the exercises are completed, then the children are always allowed some time for playing. They appreciate swimming more for its intrinsic pleasure than for its therapeutic value. "We play with the floating penguin," says Peter. "I jump on the penguin, and sometimes I miss and then I get ducked under the water; but that's what I like."

\section{The Dependent Body}

Needless to say, motor disabled children are often dependent on longterm help and help on a frequent basis. A body that refuses to do what one wants it to do, a body that is unreliable, a body that is sensitive to pain has an obvious need for help. This help can either be provided by people or it can be made available in the form of technical aids.

Handicapped children are surrounded by a large company of helpers: parents, brothers, sisters, friends, teachers, doctors, nurses, therapists, and paramedics. The help these people provide may be physically fairly neutral; for example, the teacher holds the door open, a sister pushes the chair over the threshold, and a friend carries one's bag. There is, however, also a form of help that is more specifically directed to the body and that disturbs the taken-for-granted function of the body.

In the mornings, Ilse, who has cerebral palsy, is incapable of getting out of bed without assistance. She lies frontally belted on a preformed mattress. Her younger brother unfastens the belts for her. Her father picks her up from her bed, puts her onto a shower mattress and washes her. She also needs assistance in getting dressed and in eating. On a bad day she may have to have her clothes changed at school. Soon Ilse will be going to secondary school. How do children like Ilse experience such physical dependence and the help that is entailed? It is not easy to answer this question. Young children in particular take this help rea- 
sonably for granted. Being washed, being dressed, being helped in the washroom, these are the most natural events in the world. However, the purpose of childrearing and education is to bring an end to dependence and to give children independence.

Even for healthy children the course of this process does not always run smoothly, but for motor disabled children the risks are much higher. Only minor problems seem to occur when parents, caretakers, and children regard help as objectively necessary. If it is absolutely impossible to dress oneself, then the need for help is self-evident (which does not to mean that this help and the way it is given are necessarily enjoyed).

Things become more difficult if the necessity is doubted by the child or the caregiver. The class assistants and parents of Liesbeth and Arjen feel that it is time for them to learn to apply the catheter themselves. But Liesbeth says: "If somebody else does it, it means I get to lie down, and that feels nice." And Arjen responds almost indignantly: "I'm not a nurse." He simply cannot conceive of doing it himself. The self-evidence can sometimes become too self-evident when children start to lean on the help.

The opposite seems to occur just as often. Children may be given help that is unwanted because the parents or teachers feel too anxious to pass on these responsibilities. Peter is proud that he can dress himself above the waist and that he can eat by himself. In the early morning rush, however, his parents do not grant him this independence. This is an annoyance to him.

Finally of course, some children have mixed feelings. On the one hand they are reluctant to accept help, but on the other hand it's nice and easy. Hakan has to wear a corset which involves a certain amount of lugging his body about. Does Hakan enjoy being helped with so many things? "Well, I don't really know what to say about that. I'd actually rather do everything by myself but, I suppose, I'm quite glad too that I'm helped. I like it both," concludes Hakan.

Hakan's corset is an example of the technical help that the children receive. An important function of the technical aids is to increase the children's mobility by way of wheelchairs, braces, splints, and crutches. Once the children are used to them, these devices become extensions of their bodies as it were. If something is wrong with a technical aid, then there is something wrong with the child himself or herself. If the electric wheelchair breaks down, then the taken-for-grantedness of the body is disrupted and suddenly the child cannot even move. When Erik's wheelchair has a problem, sparks fly and part of the electrical circuit is destroyed. Our repair attempts are unsuccessful and eight- 
year-old Erik cannot hold back his tears at the prospect of being immobile for the rest of the afternoon.

Special aids improve posture and movement, such as corsets, special shoes, and preformed mattresses. Unlike the wheelchair, children often do not notice an immediate supportive effect of these special aids; on the contrary, they can be awkward and painful and are not experienced as an extension of the body. Even the drain is an aid on which some children are extremely dependent, and a defective drain forces children to be reminded again of the physical dependence of their body.

\section{The Conspicuous Body}

Children with a motor disability are often conspicuous in their neighborhood. They sit in wheelchairs, electric or hand-driven, they walk with crutches, or they walk independently but not in a straight line. You may also meet motor disabled children in eye-catching vehicles such as three-wheelers and "flying Dutchmen." "Normal," healthy people seem to have difficulty with the way children with a handicap look. And so physically handicapped children feel looked at. Many children feel discomfort when caught in someone's gaze. It is as if a mirror is suddenly and uninvitedly held in front of the body that was not conscious of itself.

Annie would like to have new shoes without those thick soles "because then they won't keep looking at my shoes, and that would be less embarrassing, if they stop looking at my shoes ... People always look. Even when I go out on my bike with mom and dad. They always look at my bike because I haven't got a normal bike." This being looked at is a central experience in the life of handicapped children. Other people's looks continually remind them of their difference. When people ask the child questions about his or her disabilities, these questions too tend to cause the body to turn conspicuous and into an external theme.

Marjolein writes: "They always ask my dad, mom, or friends 'what's wrong with her?' I usually answer them myself ... For example, there was a girl at the corner and she was standing beside my friend, and she was there with her little sister too, and she asked my friend: 'What's the matter with her? What's wrong with her legs?' or something like that. And then I said: "You can ask me that, you know."

In addition to this being looked at and being questioned, motor disabled children are more commonly teased and picked on than their nonhandicapped peers. Physical traits are undoubtedly at the root of this behavior. The children are often called names such as lame duck or cross-eye or diaper-wetter. A child with cerebral palsy with facial and leg spasms may be called a mongol. And Guy, who has muscular dystrophy and can't walk any more, says, "They keep asking, can't you walk? ... A while ago I had a red push-chair and I was at a camp site 
and my cousin was there and there were two girls and they called me "Baby!' But then my cousin went after them."

Despite the fact that name-calling usually only refers to a physical trait, it still implies for the children that they are what they are called. If you are physically handicapped and they call you a lame duck, you don't just feel that as an insult to your legs; you are insulted as a whole person. You not only have this deformed body, you are this body. Depending on the nature of their handicap, children develop a variety of reactions and strategies to remain in charge of themselves and deal with the abuse:

1. Ignore them. Act as if you do not hear the other person. Looking away and think "I am not going to let it bother me." However, ignoring pests is not always easy to do and so children develop other strategies such as the following.

2. React with humor. Linda has a conspicuous swaying walk. When children ask her, "What did you do to your feet?" she answers, "I put my shoes on them."

3. Explain and ask for understanding. "I can't help it, I was born like this." Sometimes children explain further, such as: "I'm just spastic"; or they explain in more detail how they suffered from lack of oxygen at birth.

4. Get reinforcement. "I'll get my mom!" or "My big brother will get you."

5. Get angry, swear, threaten, or hit.

6. Cry. Sometimes it just gets too much and children go home in tears.

Other people's looks do not always draw attention to the body in a negative sense. Friends, parents, or people at school might also praise the child because he or she has drunk his or her milk without spilling it, or because he or she is walking erect. So the child can still experience pride in what the body can do.

The (In)comprehensible Body

Still another more complex experience of the body occurs in the life of motor handicapped children. This is a somewhat different relation to the body than described in the above sections. This is the experience of the body as it is reflected on and wondered about by the child.

The difficult or dysfunctional body often gives rise to questions such as "why can other people do this and I can't?" This is the sort of question that might be associated with the experience of the rebellious body. Some possible reactions are jealousy, negation, protest, or acceptance. 
Nine-year-old Janet sees a television program about beat-dancing for children. The girl next door goes to jazz dance classes and Janet wants her mother to let her go as well. Mother does her best to explain to Janet that dance would be too difficult for her. But Janet expresses incomprehension: "Why can I not do dance?" In her distress she experiences a silent hope that one day, some day, it might be possible. Janet does not (yet) have a realistic view of her physical limitations.

Ivar loves soccer. But sometimes he complains that he cannot play soccer for very long. He gets tired very fast. When he was a few years younger Ivar frequently used to ask his therapist: "If I practice really hard with you, will I then be able to play soccer?" But Ivar does not ask those questions any longer. He has come to a more realistic understanding of his limitations.

Arjen is preoccupied by a question that he wonders about. "How can it be that I can ride a bike but that I cannot walk?" Arjen says, "My mother does not understand it either. I can't walk, but I can ride a bike." His friend Guy explains to Arjen: "It's because when you are walking, your legs have to be straight and when you are on your bike they don't have to be." Guy is demonstrating his knowledge of the body that he may have learned from his physiotherapist.

The answers to the many questions concerning "what exactly is wrong?" remain difficult. Many younger children have only a vague idea of this difficulty. In answer to the frequent question, "what's wrong with you?" they say, "I'm handicapped." And to the question "why's that?" they respond "I was born like this" (or "none of your business!").

So what is this "being handicapped" exactly? Erik, a bright eight-yearold, wonders about the meaning of handicap. He says, "I want to talk with you about this word 'handicap,' 'cause there's such a fuss about it." He seems to associate handicap exclusively with his own motor disability; as far as he is concerned, a blind or deaf person is not handicapped. The fact that the term is also used in cases of psychic disorders, in other words, the fact that you can also be mentally handicapped is completely new to him. Most of his peers, however, hardly seem to occupy themselves with such questions. You're handicapped and that's the end of the story. When they are asked, "Which children in your class have the same handicap as you do?" they refer to physical traits: "Johan has the same as I've got, because he's in a wheelchair too." "Anne can walk and therefore she does not have the same thing as I have." Their reasoning is certainly not without logic.

Older children can often state exactly what is wrong with them and how it came about. Karel attends the regular public school and through 
a story in the school newspaper he explains to the other children what is the matter with him.

I was born in the Wilhelmina Hospital in Utrecht.

When I was born, it turned out that I had been born with water on my brain.

Straight away, they put a drain in my head.

That little machine makes the fluid in my head disappear down into my abdomen.

Later they found out that I was handicapped in my legs.

That meant I could not walk very well.

I would only be able to walk with special support for my legs.

But I'm okay now.

\section{Pedagogical Recommendations}

In everyday life the body is largely passed over, taken for granted, unnoticed, as we are immersed in our actions in the world. This takenfor-granted state is disrupted when the body draws attention to itself; for example, when we feel hunger, thirst, sickness, or pain. Or we may become aware of our bodies when we stumble, feel tired, or when someone seems to be looking at our body or at the new clothes we wear. It is in such situations that the body becomes a theme in our existence. But for physically handicapped children there are reasons for the body becoming a theme of their existence besides these "normal" situations. These children often experience situations where the body dominates existence too much. The body demands attention, whereas in fact it is the world to be learned about that needs attention. Handicapped children too often have their bodies and too rarely are their bodies. The body, as the silent base from where the world is explored and becomes known, loses its silence. When the silent, passed over, taken-forgranted state is disrupted, then the body refuses to cooperate; it distracts instead of functioning reliably-in short, the handicapped child may be threatened by his or her own corporeality.

This would seem to be a harmful situation. The typical childhood orientation to the world is disturbed and with it the way the child gives that world constructive meaning. This capacity to construct meaning is of vital importance in children's development. Accordingly, where it is at all possible we should help prevent motor disabled children from being threatened by or being at the mercy of their own corporeality. We should strive to maintain an orientation to the world or to restore as quickly as possible such orientation, so that these children too can give meaning to their world without being dominated by their bodies.

The experience of the vital body is very close to the unproblematic, taken-for-granted state of the body. It seems obvious that we should give handicapped children as much opportunity as possible to experience vitality. This does not just mean granting them leisure time, but 
also creating conditions under which vitality can be expressed. The notion of the conditional experience of vitality already suggests practical applications. For example, we can create the condition for the experience of vitality by covering a space in the house with soft cushions where children can romp about, or by allowing places in the backyard where children can race around the garden.

The rebellious body will have to be accepted by the child to a certain degree. This is a long-term process. In this context, children search for compensation in other areas. For instance, a number of children are able to compensate by their high degree of competence with computers. Stimulation of situations in which the child experiences competence and strength seems to be called for. Often it is not the whole body that rebels. "You've got such strong arms" is more positive than "you've got such weak legs."

Unreliability and sensibility of the body can be controlled to a certain degree, for example, by going to the washroom at a set time, getting sufficient rest, and wearing warm clothes. It remains somewhat unnatural, however, for children to keep thinking of such things. Accidents cannot be ruled out. Where possible, parents and teachers should make as little fuss as possible about an accident, so that the taken-forgranted experience of the body can be restored again as quickly as possible.

Although therapeutic exercise is almost always necessary and productive, we should keep asking ourselves how high is the price that the child has to pay for exercises that may lead to more independence, but also demand a great deal of time and focus the attention continually toward physical incompetence. Exercises that are given in a playful and light manner, showing noticeable results, compensate for these demands on the child's time and attention.

It does not seem advisable to emphasize the dependency of the handicapped body to the children. Both overdependency by the children themselves and smothering on the part of parents, therapists, or teachers should be prevented. It would seem more advisable to give children as much autonomy as possible in those matters in which they do not have to be dependent.

The conspicuous body is something that children can get somewhat used to and against which they learn to defend themselves. More important, however, is to work to bring about a change in the attitude of those people who turn their heads 180 degrees when they see a wheelchair go by.

Through education, or whenever they ask questions, we can assist children to make the incomprehensible body as comprehensible as 
possible. A matter-of-fact attitude is not suitable here. Doctors, paramedics, teachers, and parents have to provide the children with as much information as possible about matters that concern their bodies. Children often understand more than adults think; and understanding can restore peace of mind.

Notes

1. This phenomenological study of the experiences of physically handicapped children is part of the Utrecht Lifeworld Research Project. The question we ask is: How do these motor disabled children think about their lives? The research focuses on elementary school aged children who do not suffer from any mental handicaps. The few studies dealing with young people are primarily concerned with adolescent problems of ego development, arguing that there exist no existential problems during earlier childhood phases. From an adult perspective, there may be some measure of truth in this. It holds no comfort, however, for young children who are stared at and teased because of an obvious physical disability.

2. The hospital is such an extensive subject that we would like to give it a great deal more attention at a later stage in our research. We give only one quote here.

\section{References}

Bleeker, H., \& Mulderij, K.J. (1984). Pedagogiek op je knieën. Meppel: Boom.

Merleau-Ponty, M. (1962). Phenomenology of perception. London: Routledge \& Kegan Paul.

Nolan, C. (1987). Under the eye of the clock: The life story of Christopher Nolan. London: Weidenfeld and Nicholson.

Sartre, J.P. (1943). L'être et le néant. Paris: Gallimard.

Van den Berg, J.H. (1950). Menselijk lichaam, menselijke beweging. Nederlands Tijdschrift voor de Psychologie, (N.R. 4 and 5), 267-299; 401-429. 